\title{
Investigation of Trap States in AllnN/AIN/GaN Heterostructures by Frequency-Dependent Admittance Analysis
}

\author{
ENGIN ARSLAN, ${ }^{1,4}$ SERKAN BÜTÜN,${ }^{1}$ YASEMIN ŞAFAK, ${ }^{2}$ \\ and EKMEL OZBAY ${ }^{3}$ \\ 1.-Nanotechnology Research Center - NANOTAM, Bilkent University, 06800 Ankara, Turkey. \\ 2.-Department of Physics, Faculty of Science and Arts, Gazi University, Teknikokullar, 06500 \\ Ankara, Turkey. 3.-Department of Physics, Department of Electrical and Electronics Engi- \\ neering, Nanotechnology Research Center - NANOTAM, Bilkent University, 06800 Ankara, \\ Turkey. 4.—e-mail: engina@bilkent.edu.tr
}

We present a systematic study on the admittance characterization of surface trap states in unpassivated and $\mathrm{SiN}_{x}$-passivated $\mathrm{Al}_{0.83} \mathrm{In}_{0.17} \mathrm{~N} / \mathrm{AlN} / \mathrm{GaN}$ heterostructures. $C-V$ and $G / \omega-V$ measurements were carried out in the frequency range of $1 \mathrm{kHz}$ to $1 \mathrm{MHz}$, and an equivalent circuit model was used to analyze the experimental data. A detailed analysis of the frequency-dependent capacitance and conductance data was performed, assuming models in which traps are located at the metal-AlInN surface. The density $\left(D_{\mathrm{t}}\right)$ and time constant $\left(\tau_{t}\right)$ of the surface trap states have been determined as a function of energy separation from the conduction-band edge $\left(E_{\mathrm{c}}-E_{\mathrm{t}}\right)$. The $D_{\mathrm{st}}$ and $\tau_{\mathrm{st}}$ values of the surface trap states for the unpassivated samples were found to be $D_{\text {st }} \cong(4-13) \times 10^{12} \mathrm{eV}^{-1} \mathrm{~cm}^{-2}$ and $\tau_{\mathrm{st}} \approx 3 \mu \mathrm{s}$ to $7 \mu \mathrm{s}$, respectively. For the passivated sample, $D_{\text {st }}$ decreased to $1.5 \times 10^{12} \mathrm{eV}^{-1} \mathrm{~cm}^{-2}$ and $\tau_{\text {st }}$ to $1.8 \mu$ s to $2 \mu \mathrm{s}$. The density of surface trap states in $\mathrm{Al}_{0.83} \mathrm{In}_{0.17} \mathrm{~N} / \mathrm{AlN} / \mathrm{GaN}$ heterostructures decreased by approximately one order of magnitude with $\mathrm{SiN}_{x}$ passivation, indicating that the $\mathrm{SiN}_{x}$ insulator layer between the metal contact and the surface of the $\mathrm{Al}_{0.83} \mathrm{In}_{0.17} \mathrm{~N}$ layer can passivate surface states.

Key words: Capacitance, conductance, trap center, AlInN heterostructures, admittance

\section{INTRODUCTION}

AlGaN/GaN high-electron-mobility transistors (HEMTs) have been intensively studied as candidates for high-power devices, as well as high-speed and high-temperature operation. ${ }^{1,2}$ In replacing the AlGaN barrier layer with an InAlN layer in the AlGaN/GaN structure, HEMTs in turn offer potentially higher sheet charge densities because of the higher spontaneous polarization of InAlN compared with AlGaN., An important feature of the $\mathrm{Al}_{1-x} \operatorname{In}_{x} \mathrm{~N}$ alloy is the possibility to grow epitaxial layers that are lattice matched to $\mathrm{GaN}$ at an indium content $x$ of $\sim 17 \% .^{4-6}$ For lattice-matched $\mathrm{Al}_{0.83} \mathrm{In}_{0.17} \mathrm{~N} / \mathrm{AlN} / \mathrm{GaN}$, the heterostructure interface

(Received March 8, 2010; accepted August 13, 2010;

published online September 17, 2010) minimizes strain, and thereby minimizes cracking and/or dislocation formation. ${ }^{5,6}$ Because of this, AlInN/GaN-based HEMTs are superior to more conventional AlGaN/GaN HEMTs. ${ }^{7,8}$ In general, the electrical charge trap states on the surface and/or in the bulk of the heterostructure change the density of the two-dimensional electron gas (2DEG) in the channel and, therefore, limit the electronic performance of those devices in operation through the trapping/detrapping process and decrease the carrier concentration and lower the drain current, transconductance, and threshold voltage. ${ }^{7-13}$ Similarly, in GaN HEMTs, trapping effects currently place a major limitation on power performance at high frequencies. ${ }^{8-10}$ To identify and eliminate the trapping effects in $\mathrm{AlGaN} / \mathrm{GaN}^{10-12}$ and AlInN/ $\mathrm{GaN}^{7,14}$ transistors, a number of studies have been reported in the literature. Surface passivation, as one of these effects, makes it possible to reduce the 
density of surface states, thereby enhancing device performance. ${ }^{7,9,13,14}$ Recently, Pozzovivo et al. ${ }^{7}$ and Tapajna et al. ${ }^{14}$ demonstrated that an $\mathrm{Al}_{2} \mathrm{O}_{3}$ gate dielectric deposited by metalorganic chemical vapor deposition (MOCVD) strongly reduces excessive gate leakage current compared with the Schottky gate in AlInN/GaN HEMTs. Furthermore, a $\mathrm{SiN}_{x}$ insulator layer has been used successfully for surface state passivation in AlGaN/GaN HEMTs, ${ }^{10-12}$ but it has not been used for AlInN/GaN HEMT surface passivation until now.

Capacitance and conductance studies are particularly appropriate for determining the effects of trap states. ${ }^{15-19}$ The density of trap states of GaN metal-oxide-semiconductor (MOS) and AlGaN/GaN structures has been evaluated by using frequencydependent capacitance and conductance measurements. ${ }^{16,17}$ Miller et al. ${ }^{8}$ and Chu et al. ${ }^{19}$ reported on investigations of trap states in $\mathrm{AlGaN} / \mathrm{GaN}$ heterostructure field-effect transistors (HFETs), and Stoklas et al. ${ }^{9}$ reported on a trap density evaluation in $\mathrm{AlGaN} / \mathrm{GaN}$ MOS heterostructure field-effect transistors (MOSHFETs) by using similar experimental methods.

In the present work, bias-voltage- and frequencydependent capacitance and conductance measurements were performed on $\mathrm{Al}_{0.83} \mathrm{In}_{0.17} \mathrm{~N} / \mathrm{AlN} / \mathrm{GaN}$ and $\mathrm{SiN}_{x} / \mathrm{Al}_{0.83} \mathrm{In}_{0.17} \mathrm{~N} / \mathrm{AlN} / \mathrm{GaN}$ heterostructures. Frequency dispersion of admittance was observed, which was analyzed by using an equivalent circuit model. The density and time constant of the surface trap states of both of the samples were calculated. The effects of $\mathrm{SiN}_{x}$ passivation on the surface trap states are discussed herein.

\section{EXPERIMENTAL PROCEDURES}

$\mathrm{Al}_{1-y} \mathrm{In}_{y} \mathrm{~N} / \mathrm{AlN} / \mathrm{GaN}(y=0.17)$ heterostructures were grown on $c$-plane (0001) $\mathrm{Al}_{2} \mathrm{O}_{3}$ substrates using a low-pressure metalorganic chemical vapor deposition reactor (MOCVD). Prior to epitaxial growth, the $\mathrm{Al}_{2} \mathrm{O}_{3}$ substrate was annealed at $1100^{\circ} \mathrm{C}$ for $10 \mathrm{~min}$ to remove surface contamination. The growth was initiated with a 15-nm-thick lowtemperature $\left(840^{\circ} \mathrm{C}\right) \mathrm{AlN}$ nucleation layer. Then, a 520-nm high-temperature (HT) AlN buffer layer was grown at a temperature of $1150^{\circ} \mathrm{C}$. A $2.100-\mathrm{nm}$ thick undoped GaN buffer layer (BL) was then grown at $1070^{\circ} \mathrm{C}$ and at a reactor pressure of 200 mbar. After the deposition of GaN layers, a 2 -nm-thick HT-AlN layer was grown at $1085^{\circ} \mathrm{C}$ at a pressure of 50 mbar. The AlN barrier layer was used to reduce alloy disorder scattering by minimizing wavefunction penetration from the two-dimensional electron gas (2DEG) channel into the AlInN layer. ${ }^{1}$ Then, the HT-AlN layer was followed by a $17-\mathrm{nm}$-thick AlInN ternary layer. This layer was grown at $800^{\circ} \mathrm{C}$ and a pressure of 50 mbar. Finally, a 3 -nm-thick GaN cap layer growth was carried out at a temperature of $1085^{\circ} \mathrm{C}$ and a pressure of 50 mbar. The In concentration $(y)$ in the $\mathrm{Al}_{1-y} \mathrm{In}_{y} \mathrm{~N} / \mathrm{AlN} / \mathrm{GaN}$ heterostructures was determined by x-ray diffraction (XRD) measurements as $y=0.17$.

For Hall-effect measurements by the van der Pauw method, square-shaped $(5 \mathrm{~mm} \times 5 \mathrm{~mm})$ samples were prepared. Schottky contacts were made as $1.2-\mathrm{mm}$-diameter circular dots. Prior to ohmic contact formation, the samples were cleaned with acetone in an ultrasonic bath. Then, a sample was treated with boiling isopropyl alcohol for $5 \mathrm{~min}$ and rinsed in deionized (DI) water. For ohmic contact formation, Ti/Al/Ni/Au $(35 \mathrm{~nm} / 200 \mathrm{~nm} / 50 \mathrm{~nm} /$ $150 \mathrm{~nm}$ ) metals were thermally evaporated on the sample and annealed at $750^{\circ} \mathrm{C}$ for $30 \mathrm{~s}$ in $\mathrm{N}_{2}$ ambient. The measured Hall mobility and sheet carrier concentration, for the unpassivated sample, at room temperature were $820 \mathrm{~cm}^{2} / \mathrm{Vs}$ and $4 \times 10^{13} / \mathrm{cm}^{2}$, respectively. After the ohmic contact evaporation, some of the pieces of the $\mathrm{Al}_{0.83} \mathrm{In}_{0.17} \mathrm{~N} / \mathrm{AlN} / \mathrm{GaN}$ heterostructure samples were coated with the $\mathrm{SiN}_{x}$ layer by plasma-enhanced chemical vapor deposition (PECVD) with a growth rate of $10 \mathrm{~nm} / \mathrm{min}$ at $300^{\circ} \mathrm{C}$. The refraction index and thickness of the passivation layer were approximately 2.02 and $11.4 \mathrm{~nm}$, respectively, as determined by means of ellipsometry. After the passivation process, the Schottky contacts were formed on both of the samples by $\mathrm{Pt} / \mathrm{Au}(40 \mathrm{~nm} / 70 \mathrm{~nm})$ evaporation.

Current-voltage $(I-V)$ characteristics were measured using a Keithley model $199 \mathrm{dmm} /$ scanner. Capacitance-voltage $(C-V)$ and conductancevoltage $(G / \omega-V)$ measurements were performed by using an HP 4192A LF impedance analyzer in the frequency range of $1 \mathrm{kHz}$ to $1 \mathrm{MHz}$. An alternatingcurrent (AC) signal was attenuated to an amplitude of $40 \mathrm{mV}_{\mathrm{rms}}$ to meet the small signal requirement.

\section{RESULTS AND DISCUSSION}

Figure 1 compares the current density for the Schottky contact on unpassivated and $\mathrm{SiN}_{x^{-}}$ passivated $\mathrm{Al}_{1-y} \mathrm{In}_{y} \mathrm{~N} / \mathrm{AlN} / \mathrm{GaN}$ heterostructures. As expected, implementation of the $\operatorname{SiN}_{x}$ passivation layer led to significant current reduction in reverse and forward biases. The leakage current density of the $\mathrm{SiN}_{x}$-passivated heterostructures, at a bias voltage of $-4 \mathrm{~V}$, is nearly 28 times lower than that of the unpassivated samples.

Frequency-dependent capacitance and conductance measurements were carried out in a frequency range from $1 \mathrm{kHz}$ to $1 \mathrm{MHz}$ to investigate the trapping effects in the unpassivated and $\mathrm{SiN}_{x^{-}}$ passivated $\mathrm{Al}_{1-y} \mathrm{In}_{y} \mathrm{~N} / \mathrm{AlN} / \mathrm{GaN}$ heterostructures. Figure 2 shows typical experimental $C-V$ characteristics of $\mathrm{Al}_{1-y} \mathrm{In}_{y} \mathrm{~N} / \mathrm{AlN} / \mathrm{GaN}$ heterostructures measured at five different frequencies. Moreover, the experimental $C-V$ curves for the $\mathrm{SiN}_{x} /$ $\mathrm{Al}_{1-y} \mathrm{In}_{y} \mathrm{~N} / \mathrm{AlN} / \mathrm{GaN}$ sample are shown in the inset to Fig. 2. The zero-bias capacitance was approximately $528 \mathrm{nF} / \mathrm{cm}^{2}$ and $271 \mathrm{nF} / \mathrm{cm}^{2}$ at $30 \mathrm{kHz}$ for the unpassivated and passivated $\mathrm{Al}_{1-y} \mathrm{In}_{y} \mathrm{~N} / \mathrm{AlN} /$ 


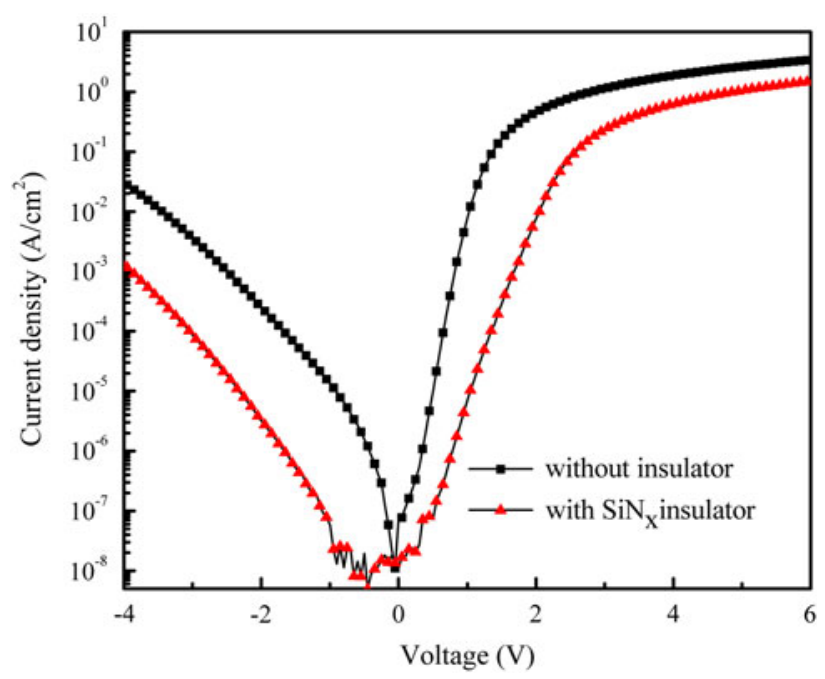

Fig. 1. Measured forward- and reverse-bias current density-voltage characteristics of Schottky contacts on unpassivated and $\mathrm{SiN}_{x}$-passivated AllnN/AIN/GaN heterostructures.

GaN heterostructures, respectively. The thickness of the AlInN barrier layer $d_{\mathrm{AlInN}}=\varepsilon_{r} \varepsilon_{0} / C_{0} \cong$ $16.4 \mathrm{~nm}$ can be evaluated considering the dielectric constant of the AlInN barrier of $\varepsilon_{\mathrm{r}}=9.8\left(\varepsilon_{0}\right.$ is the vacuum permittivity). The zero-bias capacitance of the metal-insulator-semiconductor (MIS) contact on $\mathrm{Al}_{1-y} \mathrm{In}_{y} \mathrm{~N} / \mathrm{AlN} / \mathrm{GaN}$ is lower than that of the metal-semiconductor (MS) contact on $\mathrm{Al}_{1-y} \mathrm{In}_{y} \mathrm{~N} /$ AlN/GaN heterostructures. The thickness of the $\mathrm{SiN}_{x}$ insulator layer $\left(d_{\mathrm{SiN}}\right)$ was evaluated from the zero-bias MS-to-MIS capacitance ratio, as described by $d_{\mathrm{SiN}}=\frac{\varepsilon_{\mathrm{SiN}} d_{\mathrm{AIINN}}}{\varepsilon_{\mathrm{AIINN}}}\left(\frac{C_{\mathrm{MS}}}{C_{\mathrm{MIS}}}-1\right) \cdot C_{\mathrm{MS}}$ and $C_{\mathrm{MIS}}$ are the zero-bias capacitance for the MS and MIS contact on the $\mathrm{Al}_{1-y} \mathrm{In}_{y} \mathrm{~N} / \mathrm{AlN} / \mathrm{GaN}$ heterostructure. $d_{\mathrm{SiN}} \cong$ $11.1 \mathrm{~nm}$ was obtained as the thickness of the $\mathrm{SiN}_{x}$ layer, which is in good agreement with ellipsometry measurements.

In Fig. 2 and the inset to Fig. 2, the frequency dispersion of the admittance depends strongly on the external bias at low frequency, while the change in capacitance at high frequency becomes very small. In other words, at high frequency, the trap states cannot follow the AC signal and consequently do not contribute appreciably to the capacitance. In the inset to Fig. 2, under a large reverse-bias voltage, the capacitance is small and the corresponding boundary of the depletion layer is in the GaN layer. As the reverse voltage decreases, a capacitance plateau appears, corresponding to depletion of the 2DEG located at the 2DEG channel. Further decrements in the voltage cause a new transition region, wherein the capacitance increases rapidly with decreasing reverse voltage. Moreover, another sharp capacitance slope appears on the right side of the plateau, which indicates that the depletion layer is in the AlInN layer. The surface trap states on the AlInN layer surface cause a deviation between the two curves.

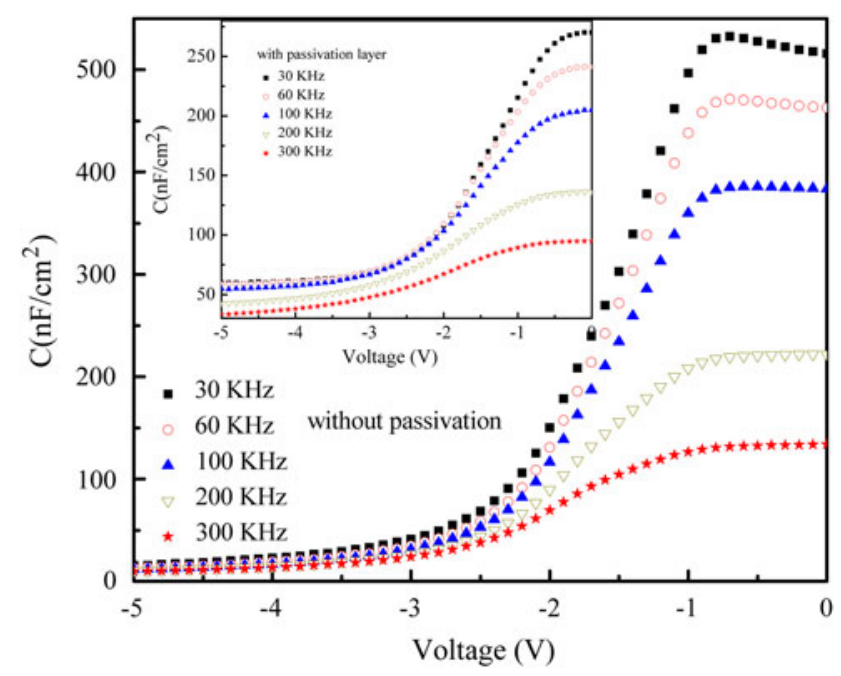

Fig. 2. Measured $C-V$ characteristics given for the unpassivated AllnN/AIN/GaN heterostructures for frequencies of $30 \mathrm{kHz}, 60 \mathrm{kHz}$, $100 \mathrm{kHz}, 200 \mathrm{kHz}$, and $300 \mathrm{kHz}$. The inset shows typical $C-V$ characteristics for passivated AllnN/AIN/GaN heterostructures.

The ohmic to Schottky contact capacitance of an ideal GaN/AlInN/AlN/GaN Schottky diode contains four components: the capacitance of (1) the fully depleted $\mathrm{GaN}$ cap layer $\left(C_{\mathrm{GaN}}\right),(2)$, the AlInN barrier layer $\left(C_{\mathrm{AlInN}}\right),(3)$ the AlN layer $\left(C_{\mathrm{AlN}}\right)$, and (4) the $\mathrm{GaN}$ depletion region $\left(C_{\mathrm{GaN}}\right)$. Hereinafter, we consider the AlN layer and AlInN layer as a single layer (because of the small thickness of the AlN layer and lower In concentration in the AlInN layer). The possibility of a lack of compositional uniformity caused by alloy clustering can generate a considerable amount of trap states at the AlInN/ AlN/GaN interface (Fig. 3a, b). The electrical behavior of the interface trap states can be modeled using capacitive $\left(C_{\text {it }}\right)$ and associated resistive terms $\left(R_{\mathrm{it}}\right)$ for the traps component, in parallel connection with the $\mathrm{GaN}$ depletion region capacitor $\left(C_{\mathrm{GaN}}\right)$. Taking into account the effect of AlInN/AlN/GaN interface trap states, the equivalent circuit of an AlInN/AlN/GaN Schottky diode is modeled as shown in Fig. 3a. In addition to the interface trap states, surface states are present at any metalsemiconductor interface. In general, for Schottky diode fabrication, the semiconductor surface is inevitably covered with a native thin insulating interfacial oxide layer if the semiconductor surface is prepared by the usual polishing and chemical etching process, in which the evaporation of metal is carried out in a conventional vacuum system. ${ }^{19-22}$ The interfacial oxide layer is only a few monolayers thick. If this layer's thickness is smaller than $30 \AA$, most of the states are in equilibrium with the metal. ${ }^{17,22}$ This trapping and detrapping process can be modeled as a serial combination of the surfacetrap-related resistance $\left(R_{\text {surf }}\right)$ and capacitance $\left(C_{\text {surf }}\right)$ in parallel connection with the interfacial oxide layer capacitor $\left(C_{\text {oxide }}\right)$. With consideration of both the interface and surface trap states, the equivalent 


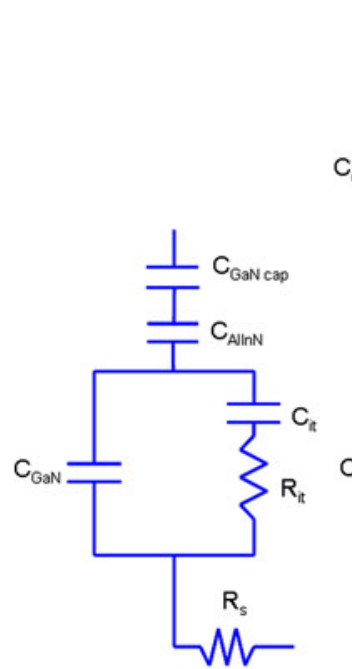

(a)

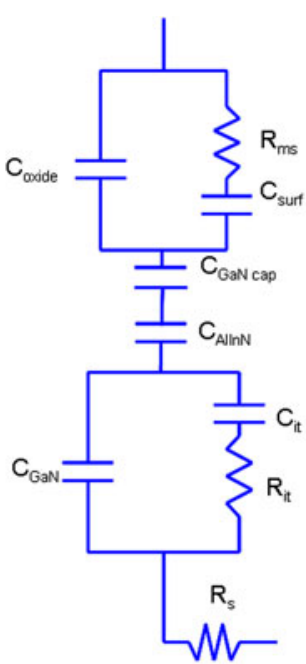

(b)

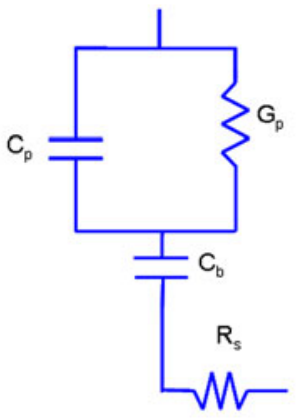

(c)

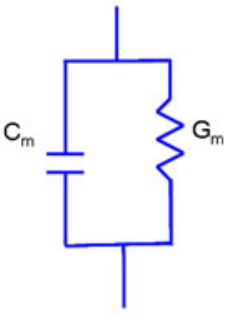

(d)

Fig. 3. Equivalent circuit model of Schottky contacts on AllnN/AIN/GaN: (a) with consideration of the interface trap states between the AllnN and GaN layer, (b) considering both the interface and surface trap states, (c) converted to a simplified circuit by considering both the interface and surface trap states, and (d) parameter extraction from the measured circuit.

circuit representation of a GaN/AlInN/AlN/GaN Schottky diode is shown in Fig. 3b. Furthermore, in addition to the interface and surface trap states, there may also be traps that are related to crystal defects and imperfections within the bulk GaN and AlInN layers. However, the bulk states have time constants as long as milliseconds, making their effects unobservable by admittance and currentvoltage measurement methods. ${ }^{8,9,19,23}$ These traps states can be detected by using the deep-level transient spectroscopy (DLTS) method. ${ }^{24}$ For these reasons, the bulk states were not considered in this analysis.

In Fig. 2, the frequency dispersion of the admittance strongly depends on the external bias, and states can be eliminated, and the effect of the surface trap states can be extracted by comparing the measured admittance values at the deep accumulation and weak depletion regime.

As shown in Fig. 3d, the capacitance and conductance of the Schottky diode were measured simultaneously, assuming a parallel combination of $C_{\mathrm{m}}$ and $G_{\mathrm{m}}$. The method described by Schroder for the interface trap states in a metal-oxide-silicon system was used in these studies for the analysis of AlInN/AlN/GaN heterostructures with care given to the surface traps. ${ }^{8,9,16,17,19,23,25}$

The parallel capacitance $C_{\mathrm{p}}$ and conductance $G_{\mathrm{p}} / \omega$ can be obtained from measured $C_{\mathrm{m}}$ and $G_{\mathrm{m}} / \omega$ curves by using the relation ${ }^{8,17}$

$$
\begin{aligned}
& C_{\mathrm{p}}=\frac{-C_{\mathrm{b}}\left[\left(C_{\mathrm{m}}^{2}-C_{\mathrm{m}} C_{\mathrm{b}}\right) \omega^{2}+G_{\mathrm{m}}^{2}\right]}{\omega^{4} C_{\mathrm{m}}^{2} C_{\mathrm{b}}^{2} R_{\mathrm{s}}^{2}+\omega^{2}\left(C_{\mathrm{b}}^{2} R_{\mathrm{s}}^{2} G_{\mathrm{m}}^{2}+C_{\mathrm{m}}^{2}+C_{\mathrm{b}}^{2}-2 C_{\mathrm{b}}^{2} R_{\mathrm{s}} G_{\mathrm{m}}-2 C_{\mathrm{m}} C_{\mathrm{b}}\right)+G_{\mathrm{m}}^{2}}, \\
& \frac{G_{\mathrm{p}}}{\omega}=\frac{-\omega C_{\mathrm{b}}^{2}\left(R_{\mathrm{s}} C_{\mathrm{m}}^{2} \omega^{2}+R_{\mathrm{s}} G_{\mathrm{m}}^{2}-G_{m}\right)}{\omega^{4} C_{\mathrm{m}}^{2} C_{\mathrm{b}}^{2} R_{\mathrm{s}}^{2}+\omega^{2}\left(C_{\mathrm{b}}^{2} R_{\mathrm{s}}^{2} G_{\mathrm{m}}^{2}+C_{\mathrm{m}}^{2}+C_{\mathrm{b}}^{2}-2 C_{\mathrm{b}}^{2} R_{\mathrm{s}} G_{\mathrm{m}}-2 C_{\mathrm{m}} C_{\mathrm{b}}\right)+G_{\mathrm{m}}^{2}} .
\end{aligned}
$$

becomes significant in the deep accumulation regime (at zero or near very small reverse voltage), in turn indicating that surface trap states are the dominant trapping mechanism in the $10 \mathrm{kHz}$ to $1 \mathrm{MHz}$ frequency range. ${ }^{8,19}$ Because of these reasons, the component related to the interface trap
In the equation, we take the barrier capacitance $C_{\mathrm{b}}$ as the total of the $C_{\mathrm{AlInN}}$ and $C_{\mathrm{GaN} \text { cap }}$ capacitance values. $C_{\mathrm{b}}$ was determined from the plateau in the $C-V$ curve associated with the accumulation of electrons in the two-dimensional electron gas channel. $R_{\mathrm{s}}$ is the series resistance of the ohmic 

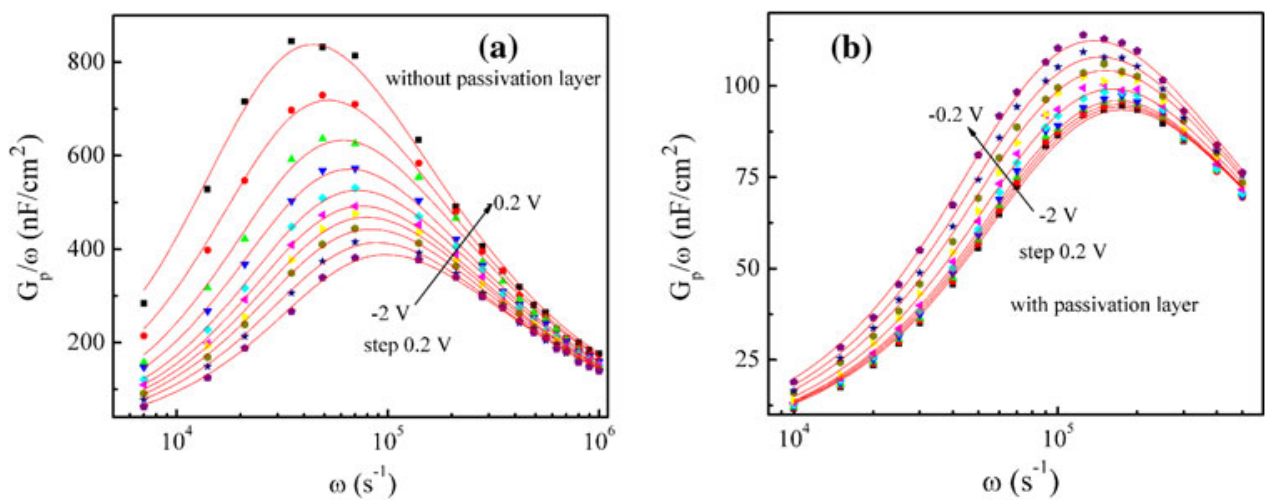

Fig. 4. Parallel conductance as a function of frequency for AllnN/AIN/GaN heterostructures: (a) without passivation and (b) with a SiN ${ }_{x}$ passivation layer, at different bias voltages. The solid curves are the best fits of Eq. $2 \mathrm{~b}$ to the experimental data.

contact. The $R_{\mathrm{s}}$ values near the origin were evaluated using a method developed by Cheung and Cheung. ${ }^{26}$

By plotting $C_{\mathrm{p}}$ and $G_{\mathrm{p}} / \omega$ as functions of frequency and by fitting the resulting curves to the equations derived by AC analysis, the surface trap density $D_{\text {st }}$ and trap state time constant $\tau_{\text {st }}$ can be extracted. The equivalent parallel capacitance $C_{\mathrm{p}}$ and conductance $G_{\mathrm{p}} / \omega$ as functions of frequency, assuming a continuum of trap levels, can be expressed as ${ }^{8,9,16,17,23,25}$

$$
\begin{gathered}
C_{\mathrm{p}}=C_{\text {oxide }}+\frac{q D_{\mathrm{st}}}{\omega \tau_{\mathrm{st}} \tan \left(\omega \tau_{\mathrm{st}}\right)}, \\
\frac{G_{\mathrm{p}}}{\omega}=\frac{q D_{\mathrm{st}}}{2 \omega \tau_{\mathrm{st}}} \ln \left[1+\omega^{2} \tau_{\mathrm{st}}^{2}\right] .
\end{gathered}
$$

Figure 4 shows the calculated $G_{\mathrm{p}} / \omega$ versus $\ln (\omega)$ curves of the $\mathrm{Al}_{1-y} \mathrm{In}_{y} \mathrm{~N} / \mathrm{AlN} / \mathrm{GaN}$ and $\mathrm{SiN}_{x} /$ $\mathrm{Al}_{1-y} \operatorname{In}_{y} \mathrm{~N} / \mathrm{AlN} / \mathrm{GaN}$ heterostructures for different bias voltages. $G_{\mathrm{p}} / \omega$ versus $\ln (\omega)$ gives a peak for each bias voltage value due to the $D_{\text {st }}$ contribution. It can be clearly seen that the peak amplitude of $G_{\mathrm{p}} / \omega$ increases and the peak position shifts to lower frequency values, when the bias voltage is varied from negative values to zero. $D_{\text {st }}$ and $\tau_{\text {st }}$ were calculated by fitting Eq. $2 \mathrm{~b}$ to the experimental $G_{\mathrm{p}} / \omega$ versus $\ln (\omega)$ curves.

Figure 5 shows the extracted $D_{\text {st }}$ and $\tau_{\text {st }}$ values as a function of energy separation from the conductionband edge. The resulting calculated parameters of the unpassivated $\mathrm{Al}_{1-y} \mathrm{In}_{y} \mathrm{~N} / \mathrm{AlN} / \mathrm{GaN}$ were $D_{\mathrm{st}} \cong(4-13) \times 10^{12} \mathrm{eV}^{-1} \mathrm{~cm}^{-2}$ and $\tau_{\mathrm{st}} \approx 3 \mu \mathrm{s}$ to $7 \mu$ s for the surface trap states, respectively. For the passivated sample, the surface states density $D_{\mathrm{t}}$ decreased to $D_{\text {st }} \cong 1.5 \times 10^{12} \mathrm{eV}^{-1} \mathrm{~cm}^{-2}$ and the time constant to $\tau_{\mathrm{st}} \approx 1.8 \mu \mathrm{s}$ to $2 \mu \mathrm{s}$. The density of the surface traps in the passivated $\mathrm{Al}_{1-y} \operatorname{In}_{y} \mathrm{~N} / \mathrm{AlN} /$ GaN heterostructures is nearly one order of magnitude lower than that in the unpassivated $\mathrm{Al}_{1-y} \mathrm{In}_{y} \mathrm{~N} / \mathrm{AlN} / \mathrm{GaN}$ heterostructures. This shows that the $\mathrm{Al}_{1-\gamma} \mathrm{In}_{y} \mathrm{~N}$ surface was successfully passivated by the $\mathrm{SiN}_{x}$ layer. The $\mathrm{SiN}_{x}$ passivation process

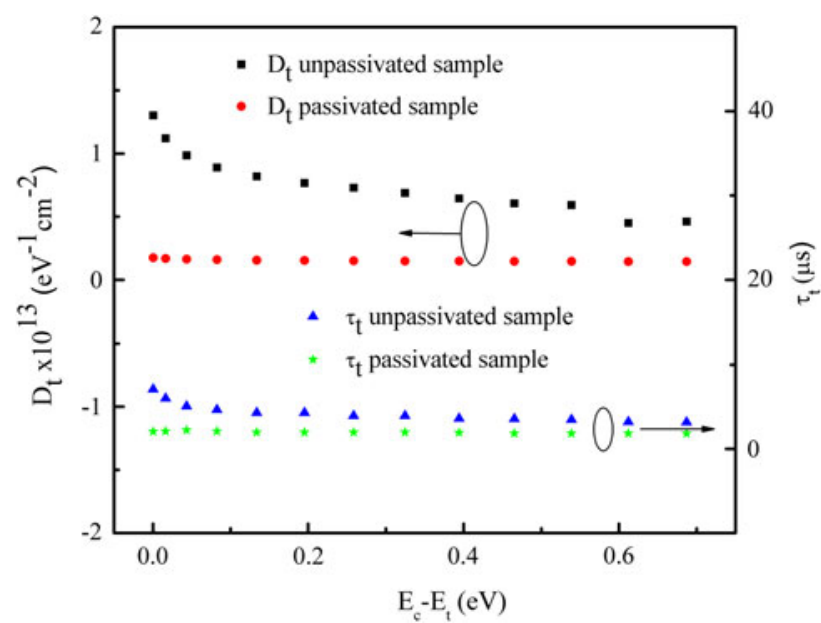

Fig. 5. Experimentally derived trap states density $\left(D_{\mathrm{st}}\right)$ and time constants $\left(\tau_{\mathrm{st}}\right)$ for interface states as a function of $E_{\mathrm{c}}-E_{\mathrm{t}}$ for unpassivated and passivated AllnN/AIN/GaN heterostructures.

is more effective for the surface traps, which are located near the conduction-band edge.

The trap states in the $\mathrm{Al}_{1-y} \mathrm{In}_{y} \mathrm{~N} / \mathrm{AlN} / \mathrm{GaN}$ heterostructures may be located at the AlInN surface, in the AlInN barrier layer, at the AlInN/AlN/GaN heterointerface, or in the GaN buffer layer. ${ }^{8,9,19}$ The trap states within the AlInN and GaN layers are usually deep below the conduction-band edge and have time constants as long as milliseconds, in which case their effects are not observable in the $10 \mathrm{kHz}$ to $1 \mathrm{MHz}$ frequency range. ${ }^{8,19}$ Miller et al. ${ }^{8}$ used various models to determine the exact location of the trap states at the heterojunction, in the bulk of the barrier layer, and at the metal-semiconductor interface. However, the location of the traps could not be determined unambiguously. Stoklass et al. ${ }^{9}$ revealed two different types of trap states, slow $(8 \mathrm{~ms})$ and fast $(0.1 \mu \mathrm{s}$ to $1 \mu \mathrm{s})$, in $\mathrm{AlGaN} / \mathrm{GaN}$ (HFETs) as well as MOSHFETs. They attributed the slow traps to surface states and assumed that the fast traps were related to bulk states. However, we attribute the measured trap states in $\mathrm{Al}_{1-y} \mathrm{In}_{y} \mathrm{~N} /$ $\mathrm{AlN} / \mathrm{GaN}$ heterostructures as surface states. 
The external bias-dependent frequency dispersion in the deep accumulation regime (at zero or near very small reverse voltage) indicates that the surface trap states are the dominant trapping mechanism in $\mathrm{Al}_{1-y} \mathrm{In}_{y} \mathrm{~N} / \mathrm{AlN} / \mathrm{GaN}$ and $\mathrm{SiN}_{x} / \mathrm{Al}_{1-y} \mathrm{In}_{y} \mathrm{~N} /$ $\mathrm{AlN} / \mathrm{GaN}$ heterostructures.

\section{CONCLUSIONS}

To investigate the trapping effects in $\mathrm{Al}_{0.83} \mathrm{In}_{0.17} \mathrm{~N} / \mathrm{AlN} / \mathrm{GaN}$ and $\mathrm{SiN}_{x} / \mathrm{Al}_{0.83} \mathrm{In}_{0.17} \mathrm{~N} / \mathrm{AlN} /$ GaN heterostructures, frequency-dependent capacitance and conductance analysis were performed using an equivalent circuit model. The density $\left(D_{\mathrm{t}}\right)$ and time constant $\left(\tau_{\mathrm{t}}\right)$ of the surface trap states have been determined as a function of energy separation from the conduction-band edge $\left(E_{\mathrm{c}}-E_{\mathrm{t}}\right)$. The $D_{\mathrm{st}}$ and $\tau_{\text {st }}$ values of the surface trap states for unpassivated samples were found to be $D_{\text {st }} \cong$ $(4-13) \times 10^{12} \mathrm{eV}^{-1} \mathrm{~cm}^{-2}$ and $\tau_{\mathrm{st}} \approx 3 \mu \mathrm{s}$ to $7 \mu \mathrm{s}$, respectively. For the passivated sample, the $D_{\text {st }}$ values decreased to $1.5 \times 10^{12} \mathrm{eV}^{-1} \mathrm{~cm}^{-2}$ and the $\tau_{\mathrm{st}}$ values decreased to 1.8 to $2 \mu \mathrm{s}$. The surface trap states density in $\mathrm{Al}_{0.83} \mathrm{In}_{0.17} \mathrm{~N} / \mathrm{AlN} / \mathrm{GaN}$ heterostructures decreased by approximately one order with $\mathrm{SiN}_{x}$ passivation. These indicate that the $\mathrm{SiN}_{x}$ insulator layer between the metal contact and the surface of the $\mathrm{Al}_{0.83} \mathrm{In}_{0.17} \mathrm{~N}$ layer can passivate surface states effectively.

\section{ACKNOWLEDGEMENTS}

This work is supported by the European Union under the projects EU-PHOME, and EU-ECONAM, and TUBITAK under Project Nos. 106E198, 107A004, and 107A012. One of the authors (E.O.) also acknowledges partial support from the Turkish Academy of Sciences.

\section{REFERENCES}

1. U.K. Mishra, P. Parikh, and Y.-F. Wu, Proc. IEEE 90, 1022 (2002).

2. R. Vetury, N.-Q. Zhang, S. Keller, and U.K. Mishra, IEEE Trans. Electron. Dev. 48, 560 (2001).

3. A. Dadgar, F. Schulze, J. Bläsing, A. Diez, A. Krost, M. Neuburger, E. Kohn, I. Daumiller, and M. Kunze, Appl. Phys. Lett. 85, 5400 (2004).
4. F. Bernardini and V. Fiorentini, Phys. Rev. B 64, 085207 (2001).

5. M. Gonschorek, J.-F. Carlin, E. Feltin, M.A. Py, and N. Grandjean, Appl. Phys. Lett. 89, 062106 (2006).

6. J. Kuzmík, A. Kostopoulos, G. Konstantinidis, J.-F. Carlin, A. Georgakilas, and D. Pogany, IEEE Trans. Electron Dev. 53, 422 (2006).

7. G. Pozzovivo, J. Kuzmik, S. Golka, W. Schrenk, G. Strasser, D. Pogany, K. Čičo, M. Tapajna, K. Fröhlich, J.-F. Carlin, M. Gonschorek, E. Feltin, and N. Grandjean, Appl. Phys. Lett. 91, 043509 (2007).

8. E.J. Miller, X.Z. Dang, H.H. Wieder, P.M. Asbeck, E.T. Yu, G.J. Sullivan, and J.M. Redwing, J. Appl. Phys. 87, 8070 (2000).

9. R. Stoklas, D. Gregušová, J. Novák, A. Vescan, and P. Kordoš, Appl. Phys. Lett. 93, 124103 (2008).

10. B. Heying, I.P. Smorchkova, R. Coffie, V. Gambin, Y.C. Chen, W. Sutton, T. Lam, M.S. Kahr, K.S. Sikorski, and M. Wojtowicz, Electron. Lett. 43, 20071211 (2007).

11. M. Miczek, C. Mizue, T. Hashizume, and B. Adamowicz, J. Appl. Phys. 103, 104510 (2008).

12. N. Onojima, M. Higashiwaki, J. Suda, T. Kimoto, T. Mimura, and T. Matsui, J. Appl. Phys. 101, 043703 (2007).

13. J. Kuzmik, J.-F. Carlin, M. Gonschorek, A. Kostopoulos, G. Konstantinidis, G. Pozzovivo, S. Golka, A. Georgakilas, N. Grandjean, G. Strasser, and D. Pogany, Phys. Stat. Sol. (a) 204, 2019 (2007).

14. M. Tapajna, KCico, J. Kuzmık, D. Pogany, G. Pozzovivo, G. Strasser, J.-F. Carlin, N. Grandjean, and K. Frohlich, Semicond. Sci. Technol. 24, 035008 (2009).

15. M. Higashiwaki, T. Mimura, and T. Matsui, Thin Solid Films 516, 548 (2008).

16. E.H. Nicollian and A. Goetzberger, Bell Syst. Tech. J. 46, 1055 (1967).

17. D.K. Schroder, Semiconductor Material and Device Characterization, 3rd ed. (Hoboken, NJ: Wiley, 2006).

18. Ş. Altındal, H. Kanbur, İ. Yücedağ, and A. Tataroğlu, Microelectron. Eng. 85, 1495 (2008).

19. R.M. Chu, Y.G. Zhou, K.J. Chen, and K.M. Lau, Phys. Stat. Sol. (c) 0, 2400 (2003).

20. E. Arslan, S. Bütün, and E. Ozbay, Appl. Phys. Lett. 94, 142106 (2009).

21. H. Rohdin, N. Moll, A.M. Bratkovsky, and C.Y. Su, Phys. Rev. B 59, 13102 (1999).

22. H.C. Card and E.H. Rhoderick, J. Phys. D: Appl. Phys. 4, 1589 (1971)

23. K. Martens, W.F. Wang, A. Dimoulas, G. Borghs, M. Meuris, G. Groeseneken, and H.E. Maes, Solid-State Electron. 51, 1101 (2007).

24. Z.-Q. Fang, D.C. Look, D.H. Kim, and I. Adesida, Appl. Phys. Lett. 87, 182115 (2005).

25. A. Singh, Solid-State Electron. 28, 223 (1985)

26. S.K. Cheung and N.V. Cheung, Appl. Phys. Lett. 49, 85 (1986). 